\title{
Care and education in patients with diabetic late complications
}

\author{
Diabetes Education Study Group of the EASD-Workshop held at Lockenhaus Castle, Austria, \\ 23-26 June 1988
}

\author{
I. Mühlhauser, V.Jörgens and M.Berger \\ Department of Nutrition and Metabolic Diseases (WHO Collaborating Centre for Diabetes), Düsseldorf University, Düsseldorf, FRG
}

During the past decade, substantial advances have been made concerning the pathophysiology of diabetic late complications and, in particular, with regard to the medical, technical and rehabilitative possibilities in the treatment of these syndromes, including the most severe disorders of the renal and cardiovascular systems, and visual and neurological functions. Both the knowledge of the progression of these complications and potential ways to interfere with these developments as well as the training to overcome various handicaps associated with these diabetic late complications appear to require particular and dedicated methods of (psychosomatic) care and education of these patients - an area of clinical diabetology which seems to have escaped major attention; at least when compared to the current interest and symposia centered on information about, and the promotion of, (new or old) pharmaceutical drugs. To focus upon the various needs of the diabetic patient with late complications concerning up-to-date medical treatment balanced with adaequate psychological support and motivation, as well as information and training based upon paedagogic and rehabilitation systems, Dres. I.Mühlhauser, V.Jörgens and M.Berger (Düsseldorf) organised a D.E.S.G. Workshop for 24 colleagues from 19 European countries at Lockenhaus Castle in Austria, near the Hungarian border. The workshop was generously sponsored by NOVO Industri, Denmark. It brought together almost all of the founding members and the past and present officers of the Diabetes Education Study Group and, due to its venue, made possible a very strong Eastern European representation. The symposium followed the traditional Geneva-format which has become a trade-mark for D.E.S.G.-Workshops, i.e. the Thursday-evening until Sunday-lunchtime schedule devoted primarily to discussion- and working-party sessions and some practical exercises.

The workshop programme was initiated by an intensive discussion of the significance of the various aspects of the 'Health Belief Concept Model' as presented/moderated by Dr. J.P. Assal (Geneva). As every participant was encouraged to formulate and express some of his/her own beliefs, it became quite apparent from what was shared that the definition of therapeutic goals, conduct and success of any treatment do not only depend on the patients', but at least as much on the physician's and the responsible health care team's particular health beliefs. The consequences for diabetes care of these interactions between the practical, measurable guidelines and necessities of diagnostic and therapeutic procedures on one hand, and the more emotional motives and reasoning behind (quite often distinct) health beliefs of patients and their physicians were identified and discussed with increasing intensity throughout the entire workshop programme.

As to a more concrete topic, Dr. I. Mühlhauser presented the particular goals and practical problems in the treatment of the diabetic patient with hypertension. A structured treatment and teaching pro- gramme was presented (Mühlhauser et al.; Diabetic Medicine 5: 1988) and discussed in detail, which addresses the obvious difficulties with lack of compliance on the part of both physicians and patients on generally accepted diagnostic and therapeutic procedures for the treatment of hypertension. It was the unanimous opinion of all participants that the generally poor standards of hypertension care in diabetic patients must be improved by systematic attempts to implement treatment and education programmes to improve compliance through both information (to physicians and patients) and the possibility of self-care by patients - including self-monitoring of blood pressure and self-adaptation of drug dosages following particular rules. This approach is preferred to concentrating on the development and promotion of more and more costly drugs of as yet undisclosed long-term (side) effects. In fact, Dr. J.Alivisatos, The D.E.S.G. President, expressed a strong view that hypertension care (as well as other areas of chronic diseases) could profit from the positive experiences of diabetology in implementing education and self-care principles as a most effective basis for the improvement of long-term treatment standards.

The second day of the workshop was devoted to the presentation of, and training in modern techniques in the rehabilitation of visually impaired and blind patients. Ms. Goergen (Switzerland), Ms. W. Strohmaier and Ms. J. Wiesenhofer (Austria), professionals in the rehabilitation programmes for the blind in their countries, demonstrated in a most impressive fashion the various recent advances in giving help and support to visually impaired and blind patients in their private and professional lives. Various of these techniques, i.e. leading blind persons, were not only demonstrated, but the workshop participants were actively trained in them. Most, if not all, of these advanced techniques, which combine sophisticated methods of psycho-social care and support for the blind, were unknown to the diabetologists present; and were received with great interest. It was hoped that this first institutional contact between two groups of health care professionals active in quite different areas, but devoted to a common group of patients could be followed up and intensified in the future in the various countries of the participants. Finally, Dres. G. Nyberg (Sweden) and M.Berger led the workshop into a discussion of the various aspects of treatment modalities and psychological care, as analysed by Dr. A. Hirsch (Hamburg), of diabetic patients with end-stage renal failure before and during the application of different renal replacement therapies. Again, it was apparent that rapid and substantial medical and technical advances need to be matched with both intensive and structured information to the patient and personal and psychosocial care and support; both of which should take into account the individual's situation and health beliefs. Models of cooperative efforts between members of medical teams with psychologists and self-help groups of patients need to be established and evaluated in order to overcome the difficulties in the care 
of these patients. The particular experiences and expertise of the D.E.S.G. should be instrumental in fostering the development of such interactional care programmes in the future.

During the closing session, which was highlighted by a concluding address from Dr. I.Drury (Dublin) many of the factors of the health belief model presented initially were re-analysed in light of the programme of the entire workshop. The fact that one-fourth of the diabetologist participants were diabetic patients themselves underlined the crucial importance of the physician's own personal ideas, beliefs and philosophy concerning the goals, the organisation, the conduct and the eventual outcome of diabetes care - especially with regard to the diabetic patient with late complications. Dr. I. Drury summarised much of the workshop's conclusions most graciously, stating that symbolically diabetologists need to learn and extrapolate from the professionals working in rehabilitation for the blind; i.e. we must all stop trying to make patients (and colleagues) do things by pushing and forcing them - but much rather attempt to acquire new ways of gently leading and supporting them after making great efforts in informing and educating them as a basis for their own free decision-making.

Dr. I. Mühlhauser

Department of Nutrition and Metabolic Diseases

(WHO Collaborating Center for Diabetes)

University Düsseldorf

Moorenstrasse 5

D-4000 Düsseldorf

FRG

\section{Book review}

Frontiers in diabetes research. Lessons from animal diabetes, vol. II. Eds.: E. E. Shafrir, A. E. Renold. London: John Libbey 1988.560 pp., (ISBN 0-86196-154-4)

Eleazar Shafrir and the late Albert E. Renold have edited their second volume on Lessons From Animal Diabetes II based upon a most remarkable workshop held in Geneva, Switzerland, in September 1987. Even more so than the first book of this series (see my book review Diabetologia 28. 116, 1985) which followed the workshop on animal diabetes held in Jerusalem in 1982, a tremendously wide spectrum of various types and classes of animal diabetes and their specific aspects has been covered by this publication of the lectures, presentations and discussions of the Geneva workshop. The special article introducing the objectives of the workshop and animal experimentation in diabetology as such on "Definitions for diabetes types: use and abuse of the concept 'animal models of diabetes" should serve as a most comprehensive background for this area of diabetes research. This chapter, which expresses so much of the philosophy of Albert Renold's approach to animal models of diabetes, reads practically like a testimony of his school of thinking, which has influenced international diabetology so profoundly.

This particular scientific philosophy concerning the approach and the possibilities for the use of various animals in medical research has manifested itself in the editing of the entire volume.
Throughout eight chapters the reader is led into and through a world of different animals with inappropriate hyperglycaemia, different aspects of aetio-pathogenesis and hormonal and metabolic derangements as well as the late complications of these syndromes. It follows the basic approach that extrapolations towards human diabetic syndromes are - as obrious as they may seem - to be with extreme caution, if at all. Of special value is the inclusion of discussion sections concerning various selected topics. The enormous potential this kind of experimental research for our understanding of diabetes in its many various facets represents the overwhelming message of this volume. It describes the state-of-the-art of animal research in diabetology at the most up-to-date and detailed level and, at the same time, shows avenues and directions for future investigations and potential solutions. At a time when animal experimentation throughout the world is faced with difficulties, there could not have been a better advocate for the usefulness and great potential of research and lessons from animal diabetes for the biological and medical sciences. Along with my strongest recommendation of this volume Lessons from Animal Diabetes II to every diabetologist, I would like to express my admiration for the enormous effort on the part of all contributing authors, and my deepest gratitude and admiration to its two Editors.

Michael Berger (Düsseldorf) 